\title{
Roles of a Teacher in Colleges of Education
}

\author{
Azizah Saad ALRowais \\ College of Education, Salman bin Abdul-Aziz University \\ Saudi Arabia
}

\begin{abstract}
There have been a great number of changes in education systems worldwide recently. As part of the changes, the role of teachers will also change. The main objective of the present study was to investigate the roles that teachers carry out in the colleges of education in Saudi Arabia. The study employed the descriptive method to determine the roles of teachers carry out in the college of education in Riyadh and the college of education in Alkharj. Twenty English language teachers from the college of education in Riyadh and the college of education in Alkharj were selected randomly. In order to conduct the research, a questionnaire about the roles of the teachers was administered to the sample of the English teachers. Statistical procedures were applied on the data obtained. The results showed that teachers in both colleges carry out almost the same roles with different degrees of practice.
\end{abstract}

\section{Introduction}

Language teaching is concerned with more than the choice of the best syllabus. In language classrooms, students need a teacher who can understand their special needs - not one who will manipulate or direct them or decide for them how they will learn, but one who will encourage, guide and build selfconfidence and create enjoyment while learning the language .

The Kingdom of Saudi Arabia has been taking a special interest in foreign languages, a fact embodied in Education Policy Document no. (1390:15) specifically that of Article (50/114); whereas accentuation was extended over foreign languages learning as a means for transferring valuable innovations, disseminating Islam and rendering considerable services to humanity.

On the other hand, learning English language is no longer an acquisition of grammar or vocabulary only (taking into account all requirements posed on teachers and instructors to acquaint pupils with language). Language learning hinges, further, on practicing and using the language. Mastering language is measured by the student's ability to utilize and employ the language, not by her quantitative knowledge about the language.

Education has seen major changes over the past decade. Integrated teaching, problem-based learning, community-based learning, core curricula with electives or options and more systematic curriculum planning have been advocated. While the increasing emphasis on student autonomy in language education has moved the center of gravity away from the teacher and closer to the student, the teacher continues to have a key role in student learning. A good teacher can be defined as a teacher who helps the student to learn. He or she contributes to this in a number of ways.

\section{Literature Review}

The literature on language teaching emphasizes that teachers should be creative and inspire their learners to new and better forms of learning. It is the teacher's responsibility to know when students need assistance and when they are able to continue working productively without help. It is essential that students have time to explore problems [1].

The concept Role has defined as "an actor's part; one's function, what person or thing is appointed or expected to do"[2].

"What a teacher thinks teaching is ... determines the direction, tone, and styles of the teacher ... has a great influence on how teachers teach: their conceptions of what they would like students eventually to become." Teachers' beliefs, attitudes, and educational philosophy influence their instructional approach, classroom climate, and roles that they may adopt. The six-component model of creative teaching and its version for creative lessons can only be more comprehensive if we relate it to the discussion about teacher roles. A role is a person's function, the part taken by her/him in life or in any activity. It is the way in which $\mathrm{s} / \mathrm{he}$ is involved in, and what influence $\mathrm{s} / \mathrm{he}$ has on an activity or a situation. Teacher roles state the position that teachers have in a society, in schools, and classrooms, and the ways they are expected to behave in a relationship with students and other related persons [3]. 


\subsection{The Good Teacher}

In fact, even though a teacher spends the majority of the day in the classroom, the actual teaching component is only part of the job. An effective teacher understands that teaching involves wearing multiple hats to ensure that the school day runs smoothly and all students receive a quality education. Teaching differs from the old "showand-tell" practices.

The question arises as to what is a good teacher. A good teacher can be defined as a teacher who helps the student to learn. He or she contributes to this in a number of ways. The teacher's role goes well beyond information giving, with the teacher having a range of key roles to play in the education process. What one sees as good teaching, depends on what conception of teaching one has [3]. Two concepts are based on the strategies of teachercentered and student-centered education. Teachercentered strategies are focused on the teacher as a transmitter of information, with information passing from the expert teacher to the novice learner. Student-centered strategies, in contrast, see the focus as being on changes in students' learning and on what students do to achieve this rather than on what the teacher does [4].

Due to the changes of university English teaching in terms of curriculum goals, modern technologies and market demands, it is expected that English teachers should transform their roles from being traditional language teachers to being trainers, organizers, promoters, learners and researchers [5].

Educational scholars have highlighted the more complex demands now being placed on university teachers and the changing nature of their work tasks, with new academic roles and the diversification of existing ones. "There has been a significant shift" they suggest "from thinking that clever people can do everything to a recognition of the complexity and range of academic work" [6].

\subsection{Factors Influence a Teacher's Role}

There are many factors that influence how teachers approach their work and which particular strategies they employ to achieve their goals. The contexts in which teachers work have an important influence on teaching, since different settings involve teachers in different kinds of roles [7]. What is important in one society might not have the same significance in another. Thus there can be confusion in the way things are interpreted from one culture to another.

Many different and complex factors influence the roles that teachers adopt in the classroom. An appreciation of these factors is essential if we are to understand teaching activities. Although often the social and psychological factors inherent in the roles are hidden, the process of learning a language in the classroom is underpinned by the teacher/learner relationship.

There are some factors that influence the role relations between teachers and learners:

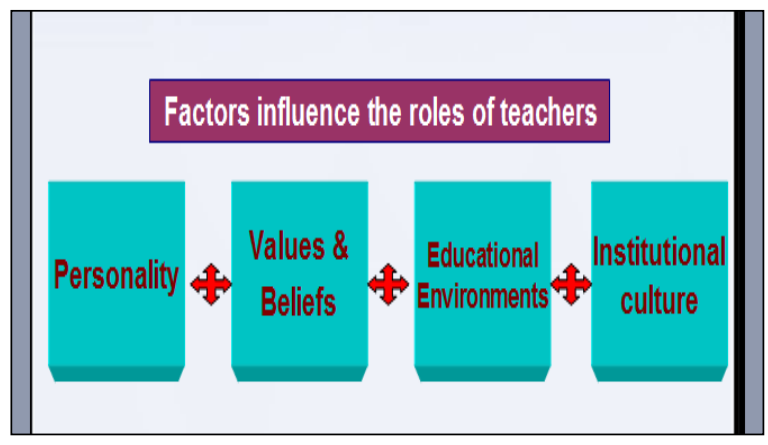

Figure 1. Factors Influence the Teachers Roles

Personality: All individuals bring their personalities into social encounters. Indeed, social life is a major factor in shaping personality. In the intimacy of the teaching/learning situation, it is extremely likely that personalities will be modified.

Beliefs: While teachers have a set of professional attitudes, personal attitudes and beliefs are likely to differ considerably between teachers and learners. The attitudes may be towards teaching and learning, the 'content' of learning or each other as people.

Educational environments: consist of learning context \& information and communication technologies.

Institutional culture: The roles of teachers reflect the institutional administrative structure, the culture operating in each institution affect rules and systems - rights and obligations.

\subsection{The Roles of Teachers}

Several studies have been carried out to investigate the effect of practicing different roles as a teacher on learning process. J R identify twelve roles of lecturer, which are grouped into six categories: the information provider, the role model, the facilitator, the assessor, the planner and the resource developer [8]. Not all the teachers aware of all these roles as some of the teachers would play all these roles while others played less roles. Thus, trainings need to be enforced to teachers so they utilize these twelve roles framework. 
Brown explains that teachers can have different roles such as controller, director, manager, facilitator, and as a resource, and concludes that "the key to interactive teaching is to play towards the upper, non-directive end of the continuum, gradually enabling your students to move from their roles of total dependence to relatively total independence" [9].

Teachers and students working together to learn and build knowledge. The widespread use of information and communication technologies enables them to create knowledge. Therefore, the broad concept of teachers' roles has already changed.

According to Harmer, the term 'facilitator' is used by many authors to describe a particular kind of teacher, one who is democratic (where the teacher shares some of the leadership with the students) rather than autocratic (where the teacher is in control of everything that goes on in the classroom), and one who fosters learner autonomy (where students not only learn on their own, but also take responsibility for that learning) through the use of group work and pair work and by acting as more of a resource than a transmitter of knowledge [10]. Harmer, also states that 'it makes more sense to describe different teacher roles in more detail:

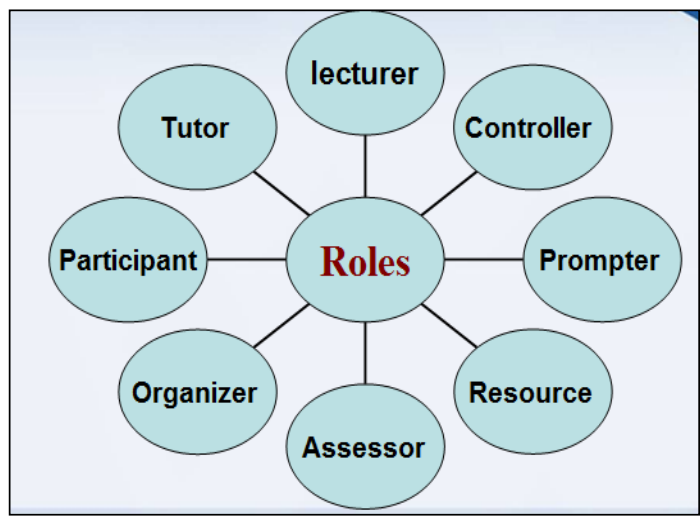

Figure 2. Roles of Teachers

- The information provider or the lecturer is a traditional responsibility of the teacher who works to pass on to students the information, knowledge and understanding in a topic appropriate at the stage of their studies. This leads to the traditional role of the teacher as one of provider of information in the lecture context.

- Controller: The teacher is in complete charge of the class, what students do, what they say and how they say it. The teacher assumes this role when new language is being introduced and accurate reproduction and drilling techniques are needed.
- Prompter: The teacher encourages students to participate and makes suggestions about how students may proceed in an activity. The teacher should be helping students only when necessary.

- Resource: The teacher is a kind of walking resource center (monitor) ready to offer help if needed or providing students with whatever language they lack when performing communicative activities. The teacher must make her/himself available so that students can consult her/him when (and only when) they wish.

- Assessor: The teacher assumes this role to see how well students are performing or how well they performed. Feedback and correction is organized and carried out.

- Organizer: Perhaps the most difficult and important role the teacher has to play. The success of many activities depends on good organization and on the students knowing exactly what they are to do. Giving instructions is vital in this role as well as setting up activities.

- Participant: This role improves the atmosphere in the class when the teacher takes part in an activity. However, the teacher takes a risk of dominating the activity when performing it.

- Tutor: the teacher acts as a coach when students are involved in project work or selfstudy. The teacher provides advice and guidance and helps students clarify ideas and limit tasks [11].

Aside from the primary role of lesson planning and classroom instruction, teacher's are taking on other roles in education. They are:

- Working with politicians, colleagues, and community members to set clear and obtainable standards for our students.

- Participating in the decision making that helps to deal with the problems that affect our students learning.

- Mentoring new teachers and getting them ready to teach the youth of today [12].

Additionally, teacher and student roles are being altered in ways that are reflective not only of the presence of technology, but also the efforts at systemic school reform. These findings highlight different roles that students and teacher adopt in the course of their interaction with technology-supported pedagogical practices that inquiry-based learning. These practices: 
- Promote active and autonomous learning in students;

- Provide students with competencies and technological skills that allow them to search for, organize, and analyze information, and communicate and express their ideas in a variety of media forms;

- Enable teachers, students, and their parents to communicate and share information on-line;

- Engage students in collaborative, projectbased learning in which students work with other classmates on complex, extended, realworld-like problems or projects;

- Provide students with individualized or differentiated instruction, customized to meet the needs of students with different achievement levels, interests, or learning styles;

- Allow teachers and students to assess student and peer academic performance [13].

\subsection{Education in Saudi Arabia}

Saudi Arabia's nationwide educational system comprises 24 government universities, more than 24,000 schools and a large number of colleges and several educational and training institutions. The system is open to every citizen and provides students with free education, books and health services. The government allocates over $25 \%$ of the total budget to education including vocational training, and spends around 13.17 billion U.S. dollars on primary education and research. All levels of education are free for Saudi nationals, and private schools are available for children of foreigners working in Saudi Arabia. These international schools offer education for children up to 14 years. Some foreign schools offer education up to 16 years.

2.4.1. Higher Education in Saudi Arabia. Comprehensive development works are taking place across the Kingdom of Saudi Arabia in all fields, and higher education is no exception; it is a pillar of the successful development in any country. A royal decree numbered $1 / 236$ in $8 / 5 / 1395 \mathrm{AH}$ (1975 AD) stipulated establishing Ministry of Higher Education to foresee executing the national higher education policy. The Minister of higher education is responsible for the execution of the government policy for university education. University education received generous support that made available new universities, colleges of science and applied fields and huge budget allocations. The twenty four government universities of Saudi Arabia, six private universities and eighteen private colleges, all of them host a plethora of disciplines that are not merelyacademic. Ministry of Higher Education is adopting contemporary trends in scientific research and strategic planning.

Those working in higher education have deeply recognized the constant changes facing in the field, from privatization to financing, foreign competition and yet the fluctuating requirements of labor market. Thus they reverted to preparing for the change by future planning and well-thought handling of these parameters; resulting in expansions, self-evaluation, initiating programs and creating organizations that focus on local and global endeavors.

\section{Statement of the problem}

The problem of the present study lies on the fact that high education teachers in Saudi Arabia carry out different roles in the colleges of education. The contexts in which teachers work have an important influence on teaching, since different settings involve teachers in different kinds of roles. The main objective of the present study was to investigate the roles that teachers carry out in the colleges of education in Saudi Arabia and to compare between the teachers' roles in the college of education in Riyadh and the college of education in Alkharj. The present study was thus an attempt to answer the following main question: (What roles do teachers carry out in the college of education in Saudi Arabia?).

From this question, the following questions emerged:

1 - What roles do teachers carry out in the college of education in Riyadh ?

2 - What roles do teachers carry out in the college of education in Al-Kharj ?

3- How similar are the roles of the teachers in the college of education in Riyadh and the college of education in Alkharj?

\subsection{Study Hypotheses}

To answer the study question, the following hypothesis was tested:

- There are no statistically significant differences at ( .05 level ) between the mean scores of the teachers' roles in the college of education in Riyadh and the college of education in Alkharj.

\section{Research Method}

In order to test the hypothesis, the study employed the descriptive method to determine the roles of teachers carry out in the college of education in Riyadh and the college of education in Alkharj. 


\subsection{Study Participants}

The study sample was composed of twenty female English teachers from the colleges of education in Saudi Arabia.Ten teachers from the college of Education in Riyadh and ten from the college of education in Alkharj, voluntarily agreed to participate in the research .

\subsection{Study Instruments}

In order to conduct the research, a questionnaire about the roles of the teachers ( designed by the researcher) was administered to the sample of the English teachers. The questionnaire consisted of a part for personal information from the participants, definitions of roles and brief instructions for completing the questionnaire .

\subsection{Delimitations of the Research}

The research was confined to:

1- A randomly selected sample of female English language teachers from the college of education in Riyadh and the college of education in Alkharj in the second term of the academic year 2013-2014

2 - Investigation of the roles that teachers carry out in their teaching.

3 - Comparison between the teachers' roles in the college of education in Riyadh and the college of education in Alkharj.

\subsection{Study Procedures}

The study procedures included the following:

1 - The researcher summarized the main roles of the teacher into specific points and used them to develop the questionnaire for investigating the roles.

2- A sample of ten female English language teachers from the college of education in Riyadh and the college of education in Alkharj was randomly selected.

3 - The questionnaire for investigating the roles of teachers was administered to all the subjects of the sample.

4 - Statistical procedures were applied on the data obtained and the results were interpreted and discussed.

5- Based on the results, conclusions and recommendations were made.

\section{Results and Analysis}

First table, I presented the results of the teachers' questionnaires from the college of education in Al-kharj concerning the teachers' perception of how often they carry out the roles while teaching. Then, I presented the results of the teachers' questionnaires from the college of education in Riyadh concerning the teachers' perception of how often they carry out the roles. At the end, I presented a comparison between the teachers' roles in the college of education in Riyadh and the college of education in Alkharj.

- The results revealed the roles of teachers which are practiced in the college of education in Al-Kharj . Comparing the means of using these roles indicated that the most practiced role in the college of education in Al-Kharj is motivator. While the roles of needs analyst, material developer, counsellor, researcher, professional planner, manager, quality controller and facilitator are less practiced than the role of motivator. The least practiced roles are mentor, teaching team member, curriculum developer, empowerer and class team member.

- The results revealed the roles of teachers which are practiced in the college of education in Riyadh. Comparing the means of using these roles indicated that the most practiced roles in the college of education in Riyadh are manager and quality controller. While the roles of needs analyst, curriculum developer, researcher , mentor, group organizer and motivator are less practiced than the roles of manager and quality controller. The least practiced roles are planner, teaching team member, material developer , empowerer, facilitator, professional, counsellor and class team member.

- Comparison between the teachers' roles in the college of education in Riyadh and the college of education in Alkharj indicated the following :

Prior to conducting the research it was hypothesized that there are no statistically significant differences at ( .05 level ) between the mean scores of the teachers' roles in the college of education in Riyadh and the college of education in Alkharj. To examine this hypothesis, the researcher has used Independent-Sample T-Test to compare between the two groups [14].

The results of the Independent-Sample T-Test indicated that:

- There are statistically significant differences at ( .035 level ) between the mean scores of the teachers' role as a counsellor in the college of education in Riyadh and the college of 
education in Alkharj in the favor of Al- Kharj teachers .

- There are no statistically significant differences at ( .05 level ) between the mean scores of the rest of the teachers' roles in the college of education in Riyadh and the college of education in Alkharj.

\subsection{Conclusions and Recommendations}

The role of the teacher is primarily an occupational role, predetermined by the nature of schools and of teaching, teachers interpret their roles in different ways depending on the kinds of institutions in which they work, the teaching methods they employ, their individual personalities, and their cultural background .

Both the two cities ( Riyadh and Al-Kharj) are located in the Central region of Saudi Arabia. The two colleges of education in Riyadh and Al-Kharj almost have similar rules and educational systems. The roles of teachers in the two colleges reflect the institutional administrative structure, the culture operating in each institution and the individual personalities of the teachers.

The teachers in both colleges carry out almost the same roles with different degrees of importance and practice. In the college of education in Al-Kharj, the roles of teachers as mentor, teaching team member, curriculum developer, empowerer and class team member have to be employed and practiced more in teaching .

The administration and the teachers in AlKharj have to work together to develop the use of these roles as stated below:

- The teacher has to develop her own course plans and syllabuses based on student needs .

- The teacher has to assist less experienced teachers with their professional development.

- Teachers need to be encouraged to work together as a team rather than to teach in isolation from other teachers in the school, and to take part in cooperative activities such as team teaching.

- The teacher has to try to take as little control or direction over the lesson as possible and lets the students make decisions about what they want to learn and how they want to learn it .

- The teacher and all the students in the class have to constitute a team and should interact like members of a team.

In the college of education in Riyadh, the roles of teachers as planner, teaching team member, material developer, empowerer, facilitator, professional, counsellor and class team member have to be employed and practiced more in teaching.

The administration and the teachers in Riyadh have to work together to develop the use of these roles as stated below :

- The teacher has to develop her own classroom materials.

- The teachers need to be encouraged to identify students who are having problems and learning difficulties, and to offer individual counsel to students who need it.

- The teacher has to continue with professional development by taking part in workshops and conferences, reading professional journals in the field, and joining professional organizations .

- The teacher has to look at planning and structuring of learning activities as fundamental to success in teaching and learning .

- The teacher has to help the students discover their own ways of learning and to work independently .

Finally, the teacher needs continuous training programs to develop herself with the world improvements. The teacher has to act as a student to continue learning and following the new approaches and educational strategies through the Internet mediated communication and through reading modern periodicals in the field.

\section{References}

[1] Alsawaie , Othman N. ( 2003 ) What Roles Do Mathematics Teachers Play When Their Students Solve Problems ?. College of Education, United Arab Emirates University, alsawaie@uaeu.ac.ae.

[2] Concise Oxford Dictionary (1982)

[3] Fernstermacher, G. D., \& Soltis, J. F. (1986) Approaches to teaching. New York: Teachers College Columbia University.

[3] Biggs J (1999). What the student does: teaching for enhanced learning. Higher Education Research \& Development 18: 1 .

[4] Harden RM, Sowden S and Dunn WR (1984). Some education strategies in curriculum development: the SPICES model. ASME Medical Education booklet no 18. Medical Education 18: 284-297.

[5] Shafie, Latisha and Nayan, Surina. The Roles of University English Teachers in Malaysia. ISSN 17984769, Journal of Language Teaching and Research, Vol. 1, No. 3, pp. 262-265, May 2010

[6] Brew A and Boud D (1998). Preparing for new academic role: An holistic approach to development. International Journal of Academic Development 1(2): 17-25. 
[7] Richards, Jack C. (1996). Reflective Teaching in Second Language Classrooms. Cambridge University Press.

[8] Harden, R. M and Crosby, J R (2000).AMEE Education Guide No 20: The good teacher is more than a lecturer - the twelve roles of the teacher. Medical Teacher, 22(4): 334-347.

[9] Brown, H. D. (1994) Teaching by Principles: An Interactive Approach to Language Pedagogy. Upper Saddle River: Prentice Hall Regents.

[10] Harmer, J. (2007), "The Practice of English Language Teaching", Pearson/Longman

[11] Veira, Ingrid (2010). Roles of Teachers in the 21st Century, Pearson Education

[12] Cox, Janelle (2014). What is the Role of a Teacher? About.com:

http://k6educators.about.com/od/becomingateacher/f/Wh at-Is-The-Role-Of-A-Teacher.htm

[13] McGhee, Ray \& Kozma, Robert (2003). New Teacher and Student Roles in the Technology-Supported Classroom. SRI International 6/23/2003form, pseu

[14] Al-Duhian, Saud \& Hassan, Izat (2002). Statistical Data Analysis Using SPSS 10. Riyadh: Al-ObikanLibra 